\title{
SANDWICH DESIGN MODEL FOR ALUMINUM AND KENAF-POLYESTER COMPOSITE
}

\author{
Taufik Roni Sahroni \\ Industrial Engineering Department, BINUS Graduate Program - Master of Industrial \\ Engineering, Bina Nusantara University 11480, Jakarta, Indonesia. \\ Nurul Farah Adibah Mohd \\ Faculty of Manufacturing Engineering, Universiti Teknikal Malaysia Melaka, \\ Hang Tuah Jaya, 76100 Durian, Tunggal, Melaka, Malaysia
}

\begin{abstract}
This paper presents the design and analysis of the sandwich model for casted metalnatural fiber composite. The objective of this research is to analyze the sandwich model of natural fiber composite to be introduced in metal matrix alloys for engineering application purposes. The sandwich model is the hybrid material combined with layers aluminum LM6 and kenaf composite laminated. Overall thickness for each design is $35 \mathrm{~mm}$. For the sandwich design, each layer of LM6 is $10 \mathrm{~mm}$ thickness and each layer of kenaf-polyester composites is $15 \mathrm{~mm}$ to make it 3 layers with $35 \mathrm{~mm}$ thickness. The dimensions for both models are referring based on the requirement of ASTM C393, Standard Test Method for Flexural Properties of Sandwich Construction. Based on the simulation results, it is feasible to use the sandwich model of LM6 with kenaf-polyester composite. In addition, this simulation result strongly supports the potential for this hybrid laminate of LM6 and kenaf-polyester composite as a substitute for solid LM6, reducing the usage of LM6 substance and introducing natural fiber element into engineering application.
\end{abstract}

Key words: Sandwich design, Model, Aluminum LM6, Kenaf Fiber, Composite

Cite this Article: Taufik Roni Sahroni and Nurul Farah Adibah Mohd, Sandwich Design Model for Aluminum and Kenaf-Polyester Composite. International Journal of Advanced Research in Engineering and Technology, 10(5), 2019, pp. 95-102.

http://iaeme.com/Home/issue/IJARET?Volume=10\&Issue=5

\section{INTRODUCTION}

The design and manufacturing has been challenged to reduce the use of metal materials in order to reduce the weight and production cost. The advantages of these composite structures compared to the traditional metallic materials are superior bending stiffness, outstanding thermal insulation, low weight, and ease of machining, acoustic damping, corrosion-resistance and high stability [1]. This significantly decreased the weight of vehicles and develop the sound-deadening properties of the materials, metal-plastic laminates and sandwich sheets have been industrial in modern years [2]. To reach the same structural performance as conventional 
materials with more light weight, sandwich structures are generally used as an option material [3]. In the study, because of its corrosion resistant, high energy absorption, excellent strength to weight ratio and less water absorption, polypropylene honeycomb core were used. Thermoplastic honeycomb had yet to obtain general attention on its impact response compared to metallic or aramid core materials core since it showed some outstanding results on energy absorbing properties.

Sandwich composites are pleasantly getting more popular in structural design because of their capability to significantly become more lightweight as maintaining in mechanical performance. The decreasing in weight gives some advantages as well as higher payloads, increased range and reduced fuel consumption. As they decreased the impact on the environment, they have a positive impact on cost as well. This feature, beside with many other material characteristics available through strategic choice of core material such as low water absorption, thermal insulation, sound and dielectric properties, along with others advantage a wide range of industries and applications, including marine, wind, transportation, aerospace and industry.

Metal-composite systems consist of flashing layers of fiber-reinforced polymer (FRP) composites and metal was studied and bonded by an adhesive layer [4]. They merge both the fine properties of metals such as impact, ductility and damage tolerances with the advantages of fiber composite materials properties such as high specific stiffness, high specific strength, good corrosion resistance and good fatigue resistance. The sandwich structure can be a better choice for some application of main aircraft structures, for example in lower and upper wings as well as tail sections and in the fuselage. The elevated processing temperature and pressure are necessary for a prolonged period for the composites. Since thermoplastic-based composite offer a number of benefits such as rapid manufacturing and recyclability, current concentration has focused on it.

The importance of this research scope is to support the researches done by the researchers [5-6], and to fill in the gap related to the development of natural fiber composite. The review of kenaf fiber composite was presented at the plant structure and chemical content, fiber properties reinforcing with polypropylene and its challenge to be reinforcing with polypropylene [7]. The study also included the detail properties of several type of natural fiber and processing of kenaf fiber reinforced composite. By referring and review on both of these researchers, this research had used the knowledge to continue in the development of kenaf fiber composite in engineering applications.

This research as the initial research for the whole project is focused on the kenaf fiber laminated composite with the matrix materials is compared between polypropylene and polyester [7], and the research more focused on the properties of kenaf and polypropylene as the matrix only. Furthermore, this research to continue and meant to be an additional study in the manufacturing engineering field by applying kenaf-fiber laminated composite for the metal material.

The use of natural rubber and recycled polymers and their effect as the matrix material in the reinforcement of natural fiber composite were greatly improved the quality of product [89]. The fabrication methods to be applied for the composite processing which is extrusion, calendaring, compression moulding and injection moulding [8]. Though, this research covered the study of polypropylene and polyester as applying in the reinforcement of kenaf fiber composite for the purpose in the engineering application focused on metal function.

The application of wood fiber as the additional reinforcement material besides using the natural fiber themselves [10]. The use of wood fiber is able to improve mechanical and physical properties such as tensile strength and surface functionality. Nevertheless, this research only fixed using the kenaf fiber as the reinforcement material without any additional reinforcement 
because of its superior strength and elongation value at break to be reinforced in the laminated composite.

The natural fiber composite fabrication processes which use compression and injection moulding due to intricate geometry demand by industry [11]. The article also consist the study on the strategy to improve the thermal resistance when applying to the high melting temperature of engineering polymer. However, there is a gap of study in this research since non-complicated geometry is needed to produce the laminated composite but the hot compression moulding and internal mixer is used as to be applied in the polypropylene material. The main reason is due to the raw material of polypropylene come in pallet size and need to be melted for reinforcing with kenaf fiber. Based on the previous study, it is important to study the development of natural fiber to fill the research gap with difference perspective of low cost and utilization of waste. Therefore, this paper presents the design and analysis of sandwich model of natural fiber composite to be introduced in metal matrix alloys for engineering application purposes.

\section{MATERIALS AND METHODS}

In general, 3D modelling of sandwich design is designed by using SolidWorks software complete with the simulation test. Two types of design need to be compared in this research which is $100 \%$ using LM6 material. The sandwich model is the hybrid material combined of layers LM6 and kenaf composite laminate. Overall thickness for each design is $35 \mathrm{~mm}$. For the sandwich design, each layer of LM6 is $10 \mathrm{~mm}$ thickness and each layer of kenaf-polyester composites is $15 \mathrm{~mm}$ to make it 3 layers with $35 \mathrm{~mm}$ thickness. The dimensions for both models are referring based on the requirement of ASTM C393, Standard Test Method for Flexural Properties of Sandwich Construction. The model design must be rectangular in cross section. The depth of the specimen shall be equal to the thickness $(35 \mathrm{~mm})$ of the sandwich construction, and the width shall be not less than twice the total thickness $(72 \mathrm{~mm})$, or not less than three times the dimension of a core cell (kenaf-polyester composite) and nor greater than one half the span lengths. The specimen length shall be equal to the span length $(200 \mathrm{~mm})$ plus $50 \mathrm{~mm}$ or plus one half the sandwich thickness whichever is the greater.

After complete the sandwich design, next process to be done is simulation test using SolidWorks Simulation. The simulation study is applied to both of design, LM6 model and sandwich design model. The simulation study is to define the stress, displacement and factor of safety distribution for both designs. The minimum factor of safety value must be higher than 1 in all location of the part which indicates that the material at the location has no yielded and safe design. The forces and span length locations must be referred to the procedure stated in ASTM C393.

Static study is applied in the simulation study while the bottom lines or span length lines are set up as fixed geometry as shown in Figure 1(a) while the force is applied to the upper surface of the material with $30 \mathrm{kN}$ total load. For sandwich design, the fixed geometry is applied at the same location as LM6 which is on the both line at the bottom (Figure 1(b)). The lines at the upper surface show the force is applied on the top of material with $30 \mathrm{kN}$ load. In the sandwich design simulation study, each surface is bonded together in global bonding which directly interact to each other. All faces are touching and will move together. 


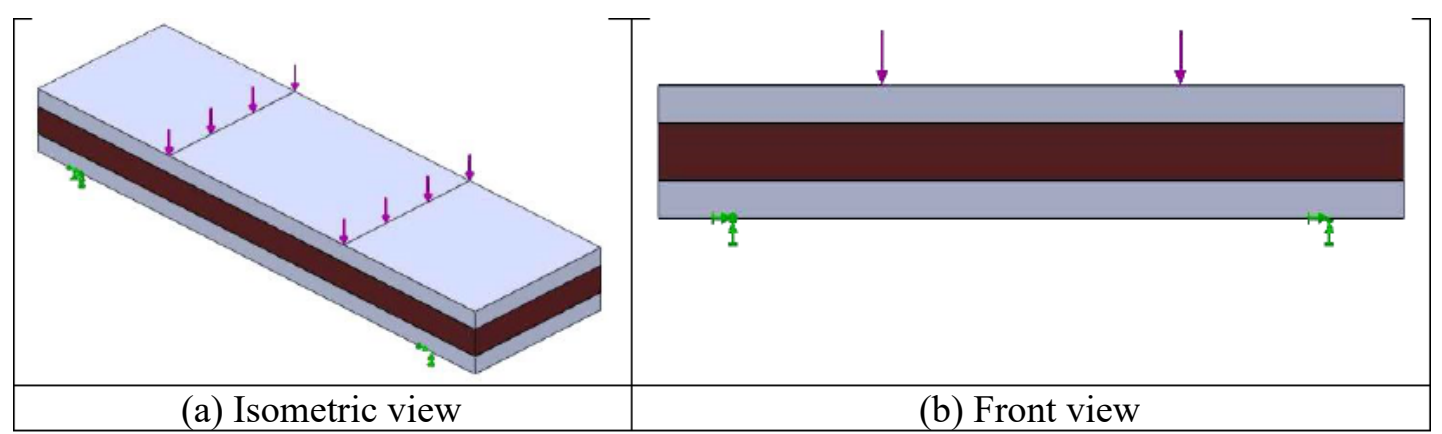

Figure 1 Force and fixed geometry location for sandwich design

After completing set up the features, the simulation study is run to get the result of stress, displacement and factor of safety. The result is shown in chapter 4 . Stress will be indicated at their minimum and maximum value and same with the displacement. The region of stress and displacement value will be in colouring range from red to blue. The minimum factor of safety for both model must be higher than value 1, else if, the model will be redesign and doing the same simulation process.

\section{RESULTS AND DISCUSSIONS}

The model simulation in Figure 2 shows performed on multilayer of 3 LM6 material and 2 kenaf-polyester composites being combined alternately. Applied with the same force as previous simulation of $30 \mathrm{kN}$, this combined layer shows that static nodal stress is largely distributed on the top layer of LM6, close to the edge of the fixed lines at the bottom. Maximum static nodal stress value is calculated at $124.4 \mathrm{MPa}$ which is not too difference with the maximum stress occurred in LM6 model. A moderate value of nodal stress is also seen in the middle portion which defined by the green contour ranging between $41.6 \mathrm{MPa}$ to $83.0 \mathrm{MPa}$.

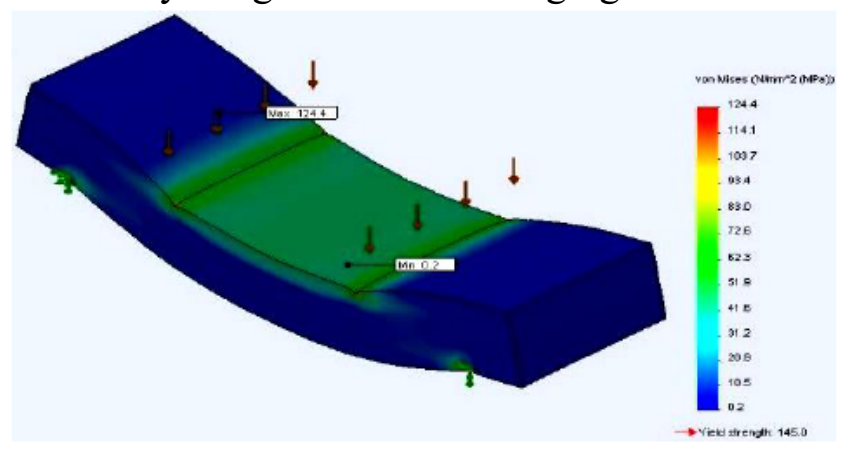

Figure 2 Static Nodal Stress of sandwich model

A relatively lower nodal stress value is shown on the kenaf-polyester composite layers as compared to LM6 layers. The minimum value is defined at $0.2 \mathrm{MPa}$ which is similar value to the stress minimum in LM6 model. Focusing the explanation on the first two upper layers of LM6 and kenaf-polyester composite respectively, the first layer of LM6 shows more stress gathered on its top surface induced by the direct load of $30 \mathrm{kN}$. However, the bottom surface of this LM6 layer is also showing some amount of stress. This can be explained by the presence of the second layer of kenaf-polyester composite under the LM6. Kenaf-polyester composite layer shows higher resistance to stress, therefore holding back the LM6 layer from further deformation. This creates a sandwich effect where LM6 is squeezed in the middle between the $30 \mathrm{kN}$ load and kenaf-polyester composite layer, developing a moderate stressed area at the bottom surface of this particular LM6 layer. The same scenario happens on the next alternate layers of LM6 and kenaf-polyester composite but with lesser stress since most of the applied force is already absorbed by the top LM6 layer. Overall, the simulation shows that kenaf- 
polyester composite presents higher strength which tends to resist the stress from applied load. LM6 with the lower strength tends to be salvaged with most amount of stress from the applied load. The presence of kenaf-polyester composite in between layers of LM6 material has produced variety of material strength in one solid model, resulting distribution of the nodal stress in a larger surface area, mainly at the top and bottom surfaces of all three LM6 layers.

Almost same to the section clipping for the stress distribution of LM6 model, the maximum value is occurred along the forces line and fixed geometry lines (Figure 3). Medium of value is shows on the top surface between 2 lines of the forces applied. This result show, the addition of kenaf-fiber composite at the center layer of sandwich offer nearly the same stress occurred to the $100 \%$ LM6 model.
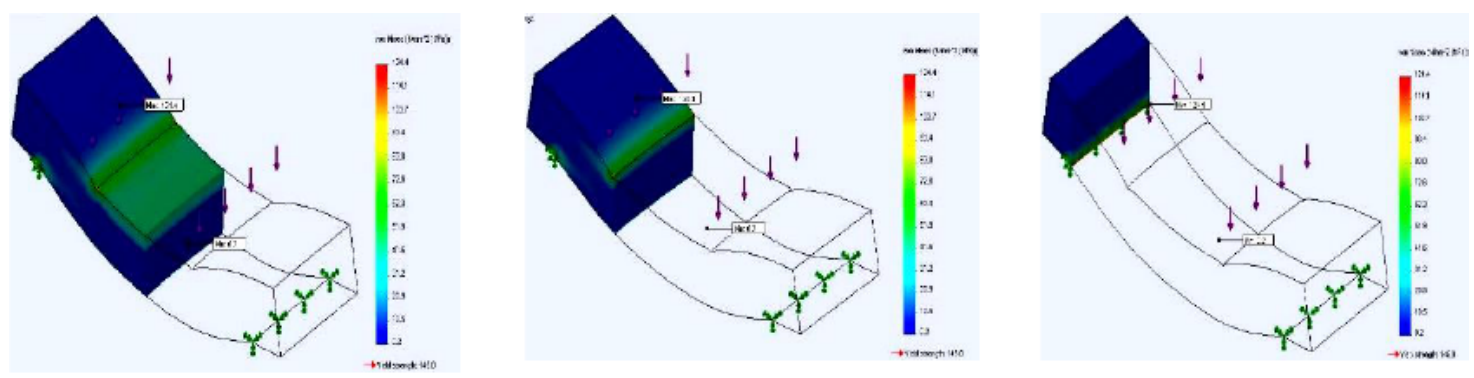

Figure 3 Stress distribution for sandwich design

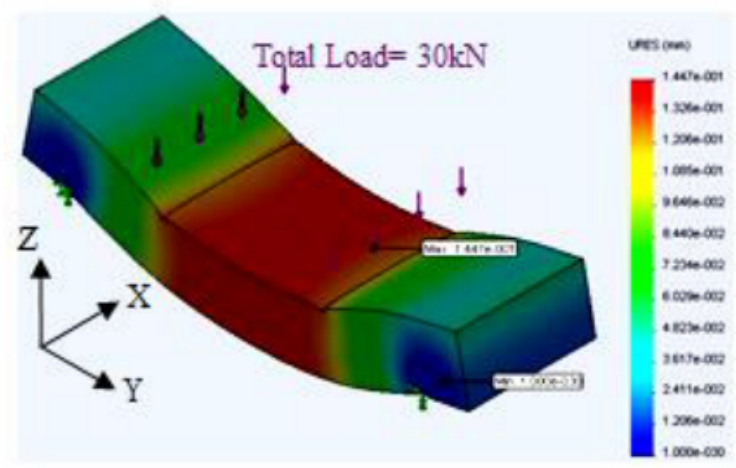

Figure 4 Static displacement of sandwich model

This next simulation result in Figure 4 is the static displacement occurred on the combined structure of LM6 and kenaf-polyester composite. Loaded with a uniform $30 \mathrm{kN}$ force at the top surface at negative $\mathrm{Z}$ direction and focusing at the lines, this model shows maximum displacement at the middle portion of the upper LM6 layer calculated at $0.1447 \mathrm{~mm}$, parallel to the applied load. Minimum displacement is shown at both fixed sides of surface B and the opposite surface with the reading of 10-30 mm. Focusing on the middle portion of the second layer of kenaf-polyester composite, large displacement is shown in red contour only on its top surface. The bottom surface of this layer shows lesser displacement which indicated in yellow contour. This condition suggested that kenaf-polyester composite holds higher rigidity property, resisting the displacement transferred from the first layer LM6 and reducing the displacement needed to undergo by the third layer of LM6. This condition is repeating for the next alternate layers of kenaf-polyester composite and LM6, resulting the middle portion of the last LM6 layer experience the least displacement compared to the other two upper LM6 layers. The simulation result clearly portrays the reduction of static displacement on LM6 from top to bottom layers by the colored contour from red to yellow and green respectively, due to the presence of kenaf-polyester composite in between the LM6 layers. 
The displacement distribution area made a difference with the LM6 model only at the maximum and minimum value of displacement. The maximum value of sandwich design is a bit higher than LM6 model with $0.045 \mathrm{~mm}$. Refer to Figure 5, the section clipping area of displacement of sandwich design also created the nearly same distribution with the LM6 model. This result show, the application of kenaf-polyester composite in this sandwich design allows the model to have the same character with the pure LM6 model.
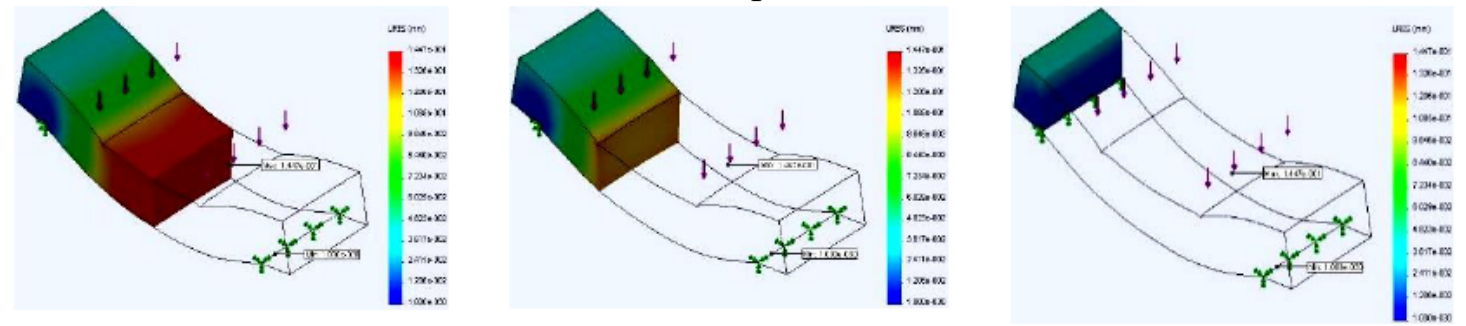

Figure 5 Displacement distribution for sandwich design

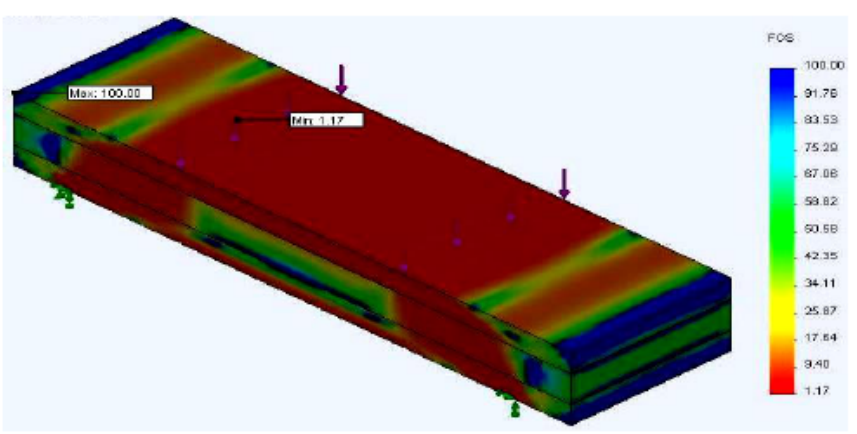

Figure 6 Factor of safety distribution of sandwich model

Figure 6 shows the factor of safety distribution on the sandwich model of LM6 and kenafpolyester composite. The same load applied as the LM6 model which is $30 \mathrm{kN}$ on the top of the surface. The factors of safety distribution area in this model same with the LM6 model which the maximum value region occurred only at certain area at the center and side surfaces. The minimum value is 1.17 which is not greatly differ with minimum value of LM6 model, 1.13 but a bit higher. Considering the comparison result, this sandwich design is still under the safe design. With the addition of kenaf-polyester composite in the layers of the sandwich, it is able to sustain the high load of $30 \mathrm{kN}$ with generate higher maximum of stress.

By refer to the section clipping view in Figure 7, it is clearly showing that the minimum factor of safety value is occurred along the forces line but the minimum value can be found at the center area inside sandwich model as shown in Figure 7(a). This minimum area is happened between the kenaf-polyester composite and the last layer of LM6 model.

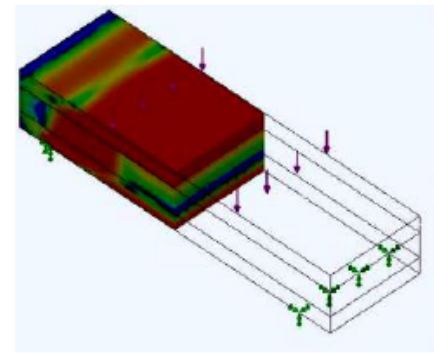

(a)
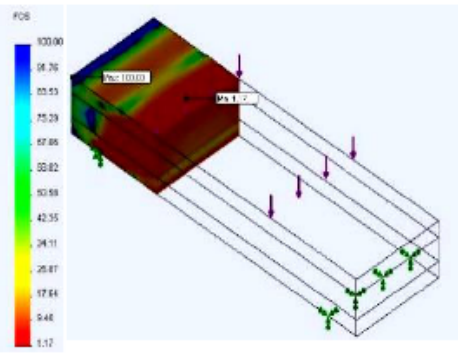

(b)
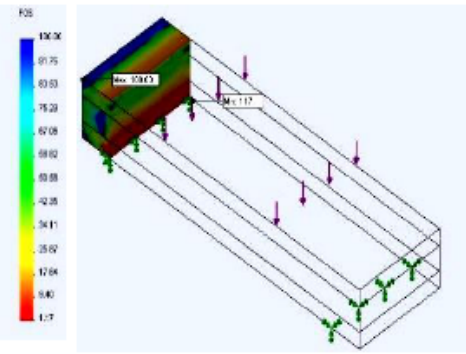

(c)

Figure 7 Factor of safety for sandwich design 
Table 1 list the summary of simulation study for sandwich model compared with solid LM6. It is found that based on the simulation criteria of static nodal stress, static displacement, and factor of safety, the use of sandwich model is potentially to be used in engineering application.

Table 1 Summary of simulation result

\begin{tabular}{clccc}
\hline No & \multicolumn{1}{c}{ Simulation } & Solid LM6 & Sandwich Model & Difference \\
\hline 1 & Static Nodal Stress & $128.8 \mathrm{MPa}$ & $124.4 \mathrm{MPa}$ & $4.4 \mathrm{MPa}$ \\
2 & Static Displacement & $0.09919 \mathrm{~mm}$ & $0.1447 \mathrm{~mm}$ & $0.04551 \mathrm{~mm}$ \\
3 & Factor of Safety & 1.13 & 1.17 & 0.04 \\
\hline
\end{tabular}

\section{CONCLUSION}

The outcome of this research has been achieved with presented of sandwich model of LM6 with kenaf-polyester composite simulation. The result shows a promising comparison between both subjects. The properties of sandwich model LM6 with kenaf-polyester composite is equally match with solid LM6 showing a relatively small differences in all three simulation results.

This simulation result strongly support the potential for this hybrid laminate of LM6 and kenaf-polyester composite as a substitute for solid LM6, reducing the usage of LM6 substance and introducing natural fiber element into engineering application. This scenario is likely to aid the industry in providing the equal performance quality material with lower material cost.

\section{ACKNOWLEDGES}

This work is supported by the Directorate General of Strengthening for Research and Development, Ministry of Research, Technology, and Higher Education, Republic of Indonesia as a part of Penelitian Terapan Unggulan Perguruan Tinggi Research Grant to Binus University entitled "Pengembangan Model Perpindahan Panas untuk Bahan Material Termaju" or "Development of Heat Transfer Model for Advanced Material" with contract number: 12/AKM/PNT/2019 and contract date: 27 March 2019.

\section{REFERENCES}

[1] Imielińska, K., Guillaumat, L., Wojtyra, R., Castaings, M. Effects of manufacturing and face/core bonding on impact damage in glass/polyester-PVC foam core sandwich panels, Composites Part B: Engineering, 39(6), 2008, pp. 1034-1041.

[2] Kim, K.J., Kim, D., Choi, S.H., Chung, K., Shin, K.S., Barlat, F., Oh, K.H., Youn, J.R., Formability of AA5182/polypropylene/AA5182 sandwich sheets. Journal of Materials Processing Technology, 139, 2003, pp. 1-7.

[3] Tan, C.Y. and Hazizan, M.A. Impact response of fiber metal laminate sandwich composite structure with polypropylene honeycomb core, Composites: Part B, 43, 2012, pp. 14331438 .

[4] Asli, G. Joining and Interfacial Properties of Aluminum/Glass Fiber Reinforced Polypropylene Sandwich Composites. Master thesis, Izmir Institute of Technology, 2009

[5] Akil, H.M. and Zamri, M.H., Performance of natural fiber composites under dynamic loading. Natural Fiber Composites: Materials, Processes and Applications, (2014), pp. 323-344.

[6] Rijswijk, K.V., Brouwer, W.D., Beukers, A., Application of Natural Fiber Composites in the Development of Rural Societies. Structures and Materials Laboratory, Faculty of Aerospace Engineering, Delft University of Technology, 2001. 
[7] Akil, H.M., Omar, M.F., Mazuki, A.A.M., Safiee, S., Z.A.M. Ishak, Z.A.M., Abu Bakar, A. Kenaf fiber reinforced composites: A review, Materials and Design Journal, 32, 2011, pp. 4107-4121.

[8] Nair, A.B. and Joseph, R. Eco-friendly bio-composites using natural rubber (NR) matrices and natural fiber reinforcements. Chemistry, Manufacture and Applications of Natural Rubber, 2014, pp. 249-283.

[9] Al-Madeed, M.A. and Labidi, S. Recycled polymers in natural fiber-reinforced polymer composites. Natural Fiber Composites: Materials, Processes and Applications, 2014, pp. 103-114.

[10] Dai, D. and Fan, M. Wood fibers as reinforcements in natural fiber composites: structure, properties, processing and applications. Natural Fiber Composites: Materials, Processes and Applications, 2014, pp. 3-65.

[11] Leong, Y.W., Thitithanasarn, Yamada, K., Hamada, H. Compression and injection molding techniques for natural fiber composites. Natural Fiber Composites: Materials, Processes and Applications, 2014, pp. 216-232.

[12] Narendiranath Babu T, Bandaru Shivasai, Vattikuti Mahesh, Prashant Reddy. Design and Analysis of Coconut Fiber Reinforced Polyester Composite Leaf-Spring. International Journal of Mechanical Engineering and Technology, 8(6), 2017, pp. 544-552.

[13] Sagar Chokshi and Piyush Gohil, Effect of Strain Rate on Tensile Strength of Natural Fiber Reinforced Polyester Composites, International Journal of Mechanical Engineering and Technology, 9(10), 2018, pp. 861-869.

[14] B. Goutham, CH. Karunakar, A. Prashanth and T. Vamshi, Development and Evaluation of Some of the Mechanical Properties of Kenaf/Polyester Cellulose Composites, International Journal of Mechanical Engineering and Technology (IJMET), Volume 5, Issue 9, September (2014), pp. 259-265. 